\title{
TENDÊNCIA DO NÚMERO DE DIAS DE Chuva no estado do Mato Grosso
}

\author{
Trend in Number of Days of Precipitation in \\ the State of Mato Grosso
}

Francisco Fernando Noronha Marcuzzo', Nayhara de Lima Oliveira² e Murilo Raphael Dias Cardoso ${ }^{3}$

fmarcuzzo@gmail.com

'Companhia de Pesquisa de Recursos Minerais - Ministério de Minas e Energia

${ }^{2}$ Instituto Federal de Goiás - Goiânia/GO

3 Universidade Federal de Goiás - Goiânia/GO

\section{Resumo}

A precipitação pluvial é uma das variáveis mais importantes do ciclo hidrológico, tornando os seus condicionantes, como o Número de Dias de Chuva (NDC), de grande importância em estudos climatológicos. Com o objetivo de analisar a tendência mensal e anual do Número de Dias de Chuva no estado do Mato Grosso, realizou-se um estudo de sua variabilidade extrema e da sua possível correlação com o fenômeno El Niño Oscilação Sul (ENOS) de intensidade moderada ou forte. Foram utilizadas médias mensais e anuais do NDC das séries históricas de dados pluviométricos, obtidos da Rede Hidrometeorológica Nacional, da Agência Nacional de Águas e do Serviço Geológico do Brasil. A série histórica utilizada foi de 30 anos (1977 a 2006). Para o tratamento estatístico, calcularam-se as médias temporais do número de dias com precipitação de 120 estações pluviométricas distribuídas no estado do Mato Grosso. Observou-se que apenas o mês de março apresentou tendência 
de aumento do NDC, para a série histórica estudada, ficando os outros meses e a média geral anual, com tendência de decréscimo no NDC do estado Mato-Grossense. Como resultados, são apresentados gráficos com as tendências de NDC para cada mês e anual, correlacionados com a intensidade do ENOS, além do histograma mensal com a média de 30 anos e para cada uma das três décadas.

Palavras-chave: La Niña, El Niño, precipitação pluviométrica.

\section{Abstract}

Rainfall is one of the most important variables of the hydrological cycle, making its constraints, as the Number of Days with Rain (NDR), of great importance in climatological studies. In order to analyze the monthly and annual trend of Number of Days with Rain in the state of Mato Grosso, we performed a study of its extreme variability and its possible correlation with the El Nino Southern Oscillation (ENSO) phenomena of moderate or heavy intensity. We used monthly and annual averages of the NDR of the historical series of rainfall data obtained from the National Hydrometeorological Network, the National Water Agency and the Geological Survey of Brazil. It was used the historical series of 30 years (1977-2006). For the statistic treatment we calculated the temporal averages of the number of days with rainfall of 120 rainfall stations distributed in the state of Mato Grosso. It was observed that only the month of March tended to increase the NDR for the historical series studied, leaving the other months and the annual general average with decreasing trend on NDR in the state of Mato Grosso. Results are presented in graphical trends of NDR for each month and year, correlated with the intensity of ENSO, and also in the monthly histogram with the average of 30 years and for each one of the three decades.

Key-words: La Niña, El Niño, rainfall.

\section{Introdução}

O estado do Mato Grosso apresenta como principal atividade econômica a agropecuária. Destaque para a produção de soja e a bovinocultura que se distribuem de forma diferenciada devido à divisão do estado em três ecossistemas: Pantanal, Cerrado e região Amazônica. O excesso ou a falta de chuva pode ser favorável ou prejudicial ao desenvolvimento da economia do estado do Mato Grosso e, dessa forma, a análise das 
precipitações é de extrema importância para seu estudo, sendo possível com a obtenção de uma coleção de observações feitas ao longo de um período histórico.

A caracterização da precipitação pluviométrica no Brasil tem como maior dificuldade a pouca disponibilidade de dados, ou sua inexistência, em algumas áreas do país (Mello et al., 2001). No contexto apresentado, um dos principais ramos de pesquisa em hidrologia e climatologia consiste da aplicação do geoprocessamento, utilizando-se de técnicas de interpolação matemática para uma melhor espacialização de dados de chuva (Mello et al., 2008). Segundo Mello et al. (2009), modelos matemáticos ajustados para estimar precipitações totais médias mensais e anual podem apresentar parâmetros estatísticos que caracterizam a espacialização de forma satisfatória.

O estudo das chuvas permite um melhor planejamento de estruturas de conservação de solo (terraços, curvas de nível) e de práticas agrícolas que visem à conservação do solo por meio de manutenção de sua cobertura, assim como outras obras (barragens, canais escoadouros) e de estruturas hidráulicas de fluxo para águas pluviais, o que justifica sua determinação (Bazzano et al., 2007).

Mellarte (1999) explana que a distribuição das chuvas ou precipitação pluvial depende da topografia local e do tipo de chuva. O autor destaca as significativas diferenças na variabilidade espacial das chuvas para distâncias pequenas $(1 \mathrm{~km})$, contudo ressalta que o grau de variabilidade muda de ano para ano e de região para região, o que torna necessárias pesquisas regionais constantes para obtenção de elementos mais significativos para a variabilidade espacial.

Marcuzzo e Costa (2012), em um estudo sobre distribuição espacial de chuvas no Mato Grosso do Sul, verificaram que a média total pluvial se distribui desigual no território do Mato Grosso do Sul, separado por três unidades fisiográficas, bioma cerrado, pantanal e mata atlântica. Assim, é observado que, para o bioma cerrado, o de maior ocorrência no estado, acumula a ocorrência de $35 \%$ de toda a precipitação média para o período histórico estudado. O pantanal, localizado a oeste do estado, fica com um total de pluviosidade de $27 \%$ da série histórica utilizada. A mata atlântica registra $37 \%$ da precipitação do estado.

$\mathrm{Na}$ análise das chuvas do estado do Mato Grosso, Marcuzzo et al. (2011) verificaram que os maiores totais pluviais se concentraram na es- 
tação do ano primavera-verão, outubro a março, correspondendo a cerca de $86,5 \%$ do volume precipitado para média histórica de 1977 a 2006. Os menores totais de chuvas ocorreram no inverno, julho a agosto, correspondendo a 13,5\%. Já abril e setembro são meses que antecedem a mudança do comportamento hídrico em Mato Grosso. Os mesmos autores também observaram que a média pluviométrica anual também se distribuiu de forma desigual ao longo do território mato-grossense, separados por três grandes unidades fisiográficas, os biomas: Amazônico, Cerrado e Pantanal. Assim, observa-se que as maiores médias pluviais encontram-se no bioma Amazônico, localizado no extremo noroeste e norte, e os menores índices estão localizados no extremo sudoeste e sul, correspondentes com o bioma Pantanal.

Brunettia et al. (2001), em um estudo sobre a variação dos totais pluviométricos no nordeste da Itália, observaram que o decréscimo no número de dias chuvosos no nordeste italiano é mais significativo do que a redução dos totais anuais da precipitação.

Fischer et al. (2009), em um trabalho com o Número de Dias de Chuva (NDC) no Rio Grande do Sul, diz que é possível ter uma ideia da intensidade da precipitação pluvial, pois, ao se analisar o mesmo total de chuva em intervalos de tempo distintos, revela-se qual a sua intensidade e a sua variabilidade quantitativa e qualitativa.

Os resultados obtidos por Silva et al. (2012) permitem concluir que a variabilidade da precipitação na região do nordeste é menor no período chuvoso do que no período seco e que os maiores valores do coeficiente de variação são associados aos menores valores de precipitação e número de dias de chuva.

Silva et al. (2009), avaliando a variabilidade anual e intra-anual da precipitação e do NDC para o estado da Paraíba, observaram que os coeficientes de variação da precipitação e do número de dias chuvosos nas microrregiões do Cariri, Seridó e Curimataú são maiores do que nas estações localizadas nas microrregiões do litoral, agreste e brejo paraibano.

Com todas as abordagens descritas anteriormente, verifica-se a escassez de estudos sobre a tendência do NDC no estado do Mato Grosso. Portanto, este estudo tem como objetivo principal analisar a variabilidade e a tendência mensal e anual do NDC no estado do Mato Grosso e a possível relação dos máximos e mínimos NDC com o moderado ou forte aquecimento ou resfriamento das águas do Oceano Pacífico. 


\section{Material e Métodos}

Localização da área de estudos e caracterização da vegetação O estado do Mato Grosso possui uma área total de $903142,7 \mathrm{~km}^{2}$ e perímetro de $5.815,15 \mathrm{~km}$, com a representação de três biomas em seu território (Figura 1). O bioma Pantanal ocupa 6,8\% do território total do estado, o bioma Cerrado representa 39,7\% e o bioma Amazônia 53,5\% da área total do estado (Figura 2).

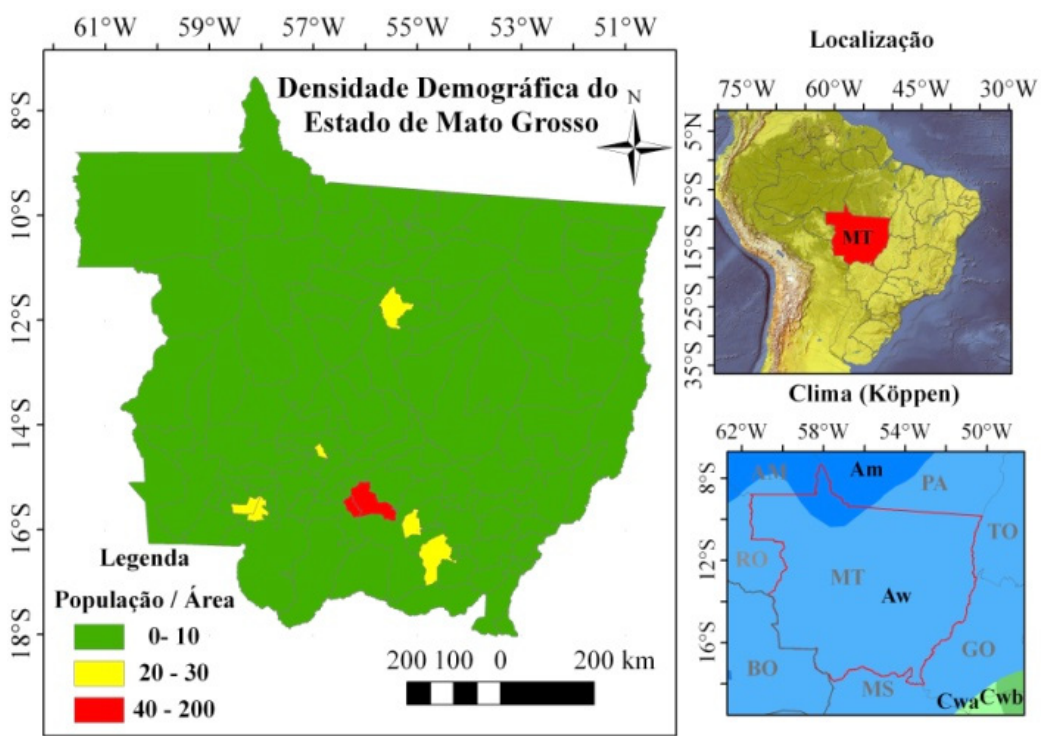

Figura 1. Densidade de habitantes por quilômetro quadrado, clima e localização do Mato Grosso

O estado de Mato Grosso possui 141 municípios (Figura 1), sendo que o maior território municipal do estado pertence ao município de Aripuana (noroeste do estado e área de $65.639,97 \mathrm{~km}^{2}$ ) e o menor é o município de São Pedro da Cipa (área de $343,89 \mathrm{~km}^{2}$, localizado a cerca de $150 \mathrm{~km}$ a leste de Cuiabá). Segundo dados do IBGE (2010), toda a população residente nos municípios do estado de Mato Grosso somam 3.035.122 pessoas, sendo que a maior densidade populacional pertence ao município de Cuiabá, com 163,88 habitantes. $\mathrm{km}^{-2}$.

No presente trabalho, foram utilizados dados do projeto SRTM (Shuttle Radar Topographic Mission), do qual foram obtidas imagens 


\section{ciênciarnatura UFSM, 34(2)}

com resolução de 90 metros, as quais foram agrupadas em um programa GIS (Geographic Information System) e, em seguida, o MDE (Modelo Digital de Elevação) foi delimitado, o que permitiu analisar a hipsometria do estado de Mato Grosso. O estado de Mato Grosso está inserido nos biomas Amazônia, Cerrado e Pantanal (Figura 2). Segundo os dados extraídos por SRTM, a amplitude altimétrica do estado de Mato Grosso varia de 44 a 1.155 metros, sendo que as regiões sudoeste e sudeste do estado apresentam as maiores altitudes (Figura 2).

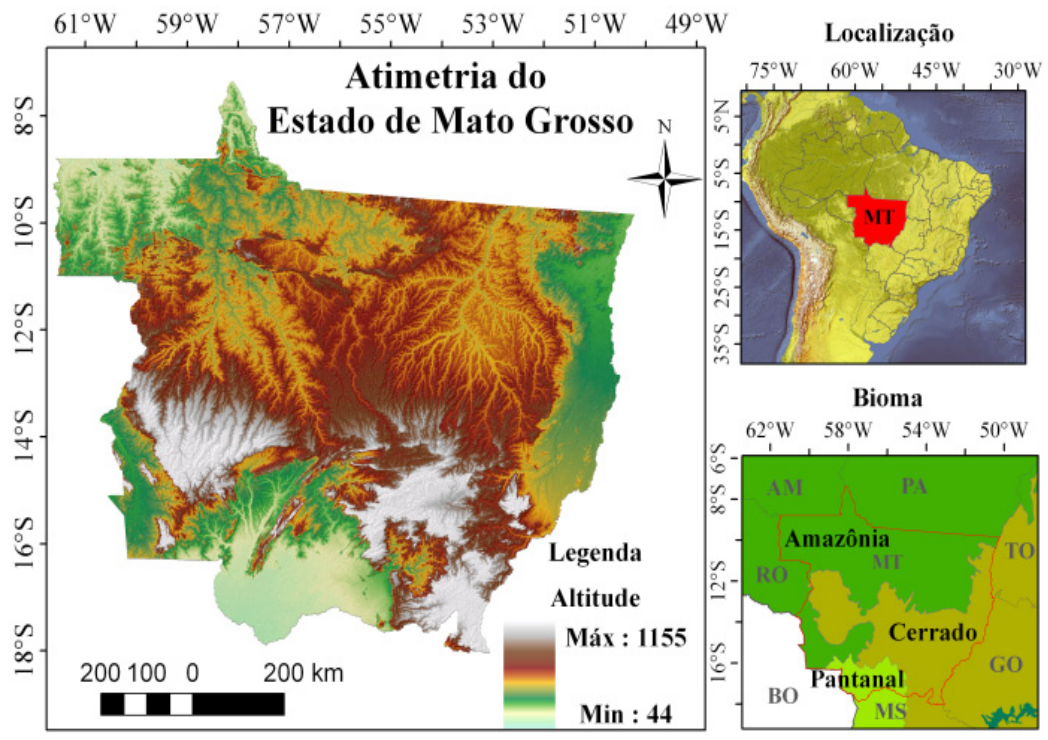

Figura 2. Relevo, localização e bioma do estado do Mato Grosso 
O uso do solo no estado de Mato Grosso se distribui entre a pecuária, agricultura e a agropecuária, porém a maior parte do solo é ocupada por vegetação remanescente (Figura 3).

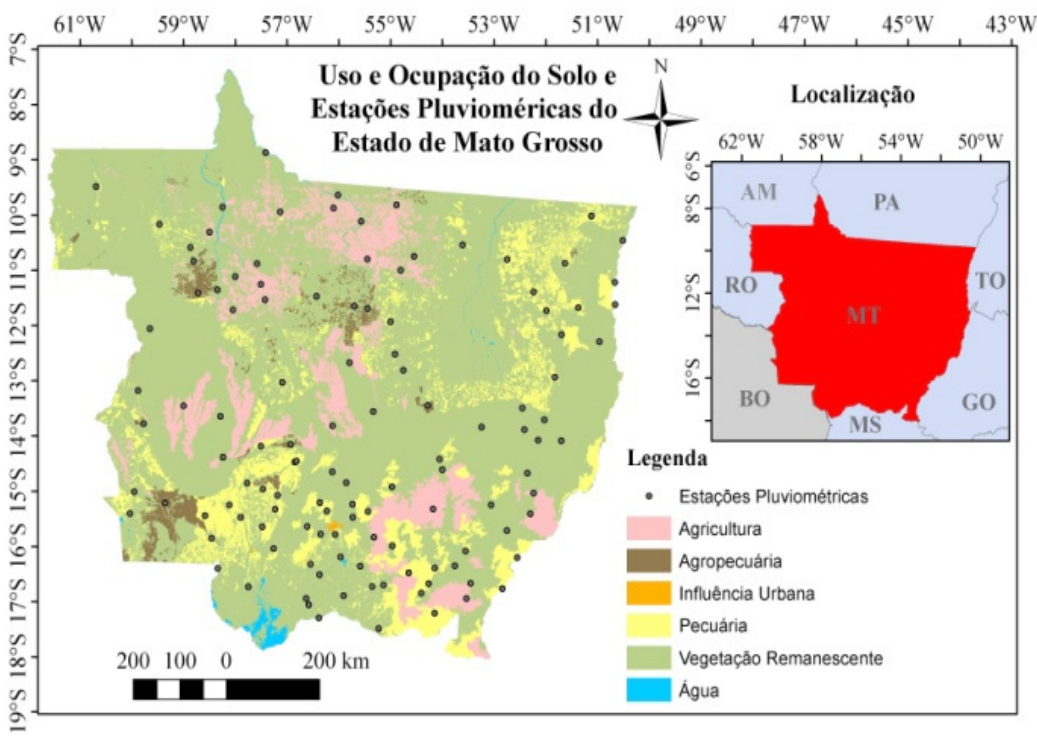

Figura 3. Uso e ocupação do solo, estações pluviométricas e localização do Mato Grosso

\section{Caracterização climatológica da área}

O estado do Mato Grosso apresenta um clima pouco complexo quanto a sua variedade de tipos de clima, segundo a classificação de Köppen, dentro dos limites do estado (Figura 1). Classificado segundo Köppen, o estado conta com dois tipos de clima: Aw, caracterizado como clima tropical com seca no inverno, que ocorre em quase todo o território do estado, e o Am, clima de monção, que ocorre apenas no extremo norte do Mato Grosso (Peel et al., 2007).

Sette (2006) cita que a extensão territorial da região centro-oeste, localizada na porção central do continente sul americano, proporciona características específicas dos Climas Continentais das latitudes intertropicais da América do Sul. Uma das principais propriedades climatológicas dessa realidade é o fato de estar situado em área de transição entre os Climas Tropicais Continentais, composto com Cerrado, e os Climas Equatoriais Continentais, integrados com a Floresta Amazônica. 
Da mesma maneira, a localização continental, distante entre 1.400 a $2.000 \mathrm{~km}$ do Oceano Atlântico, confere-lhe padrões climáticos sazonais com alternância de uma estação úmida (novembro a abril), e uma estação seca (de maio a setembro). Para Sette (2006), a grande extensão latitudinal, $\left(5^{\circ}\right.$ a $\left.25^{\circ} \mathrm{LS}\right)$ altera essa distribuição sazonal, fazendo com que a estação chuvosa no extremo meridional geralmente se inicie com um a dois meses de antecedência (setembro/outubro), enquanto no extremo norte ocorre um atraso (novembro e dezembro). Por sua vez, o início da estação seca é, da mesma maneira, antecipado no sul (março/ abril), enquanto no extremo norte, o verão amazônico só se inicia em maio/junho.

\section{Estações pluviométricas utilizadas no estudo} Utilizaram-se neste estudo 120 estações pluviométricas (Figura 3), sendo 76 estações pluviométricas com 30 anos de dados e 44 estações de apoio, com dados variando de 20 a 29 anos. Os dados diários de precipitação pluvial utilizados neste estudo foram obtidos da Rede Hidrometeorológica Nacional da Agência Nacional de Águas (ANA) e da CPRM/ SGB' (Companhia de Pesquisa de Recursos Minerais / Serviço Geológico do Brasil). Esses dados de NDC correspondem a uma série histórica de 1977 a 2006 e foram compilados, consistidos, organizados e tratados estatisticamente, com informação diária, mensal, anual e sazonal.

\section{Regressão linear e estatística}

A regressão linear é um método para se estimar a condicional (valor esperado) de uma variável $\gamma$, dados os valores de algumas outras variáveis $x$. A regressão, em geral, trata da questão de se estimar um valor condicional esperado. Em muitas situações, uma relação linear pode ser válida para sumarizar a associação entre as variáveis $\mathrm{Y}$ e X.

Assim, podemos apresentar um modelo de regressão linear simples:

$$
Y=\beta_{0}+\beta_{1} X
$$

em que, $\mathrm{Y}$ - variável dependente; $\beta_{\mathrm{o}}$ e $\beta_{1}$ - coeficientes da regressão; $\mathrm{X}$ - variável independente.

\footnotetext{
' http://www.cprm.gov.br/publique/cgi/cgilua.exe/sys/start.htm?infoid=1351\&sid=9
} 
Através da estatística descritiva, podemos ter características essenciais para a formação de histograma de frequências relativas de uma amostra de dados hidrológicos (Naghettini \& Pinto, 2007). Para este estudo, foram calculadas as seguintes medidas de tendência central e de dispersão.

A média é a medida (Galvani, 2011):

$$
X=\frac{\mathrm{X}_{1}, \ldots, \mathrm{X}_{\mathrm{n}}}{\mathrm{N}}=\frac{1}{\mathrm{~N}} \sum_{\mathrm{i}=1}^{\mathrm{N}} \mathrm{X}_{1}
$$

em que $X$ - é a média; $N$ - tamanho da amostra; $X_{1}$ até $X_{n}$ - somatórios da amostra.

Mediana $\left(X_{\text {med }}\right)$ é outra medida de posição (Galvani, 2011):

$$
X_{\text {med }}=\frac{X_{\left(\frac{N}{2}\right)}+X_{\left(\frac{N}{2}+1\right)}}{2}
$$

em que, $N$ - tamanho da amostra; $X$ - posições das amostras.

O desvio padrão é fortemente influenciado pelos menores e maiores desvios, constituindo-se na medida de dispersão mais frequentemente usada. É calculado pela seguinte expressão:

$$
S=\sqrt{\frac{1}{N-1} \sum_{I=1}^{N}\left(X_{1}-X\right)^{2}}
$$

em que $N$ - tamanho da amostra; $X_{i}$ - valor de cada amostra; $\bar{X}$ - média.

Utilizando-se as medidas de tendência central e de dispersão, pode-se verificar analiticamente os parâmetros e observar se as amostras são diferentes ou semelhantes. 


\section{Índice Oceânico Niño(a)}

No Quadro 1 e 2, observa-se a intensidade do fenômeno ENOS que foi classificada em classes fraca, moderada e forte utilizando-se a média do ION.

Quadro 1. Critérios para classificar a intensidade do fenômeno ENOS usado no estudo.

\begin{tabular}{|c|c|c|}
\hline Evento & Índice Oceânico Niño & Intensidade \\
\hline \multirow{3}{*}{ El Niño } & $0,5 \mathrm{a}$ o,9 & Fraca \\
\cline { 2 - 3 } & $1,0 \mathrm{a} 1,4$ & Moderada \\
\cline { 2 - 3 } & $\geq 1,5$ & Forte \\
\hline \multirow{3}{*}{ La Niña } & $-0,5 \mathrm{a}-0,9$ & Fraca \\
\cline { 2 - 3 } & $-1,0 \mathrm{a}-1,4$ & Moderada \\
\cline { 2 - 3 } & $\leq-1,5$ & Forte \\
\hline
\end{tabular}

Fonte: Golden Gate Weather Services (2008).

Quadro 2. Classificação anual da intensidade do fenômeno ENOS 3.4 usado no estudo.

\begin{tabular}{|c|c|c|c|c|c|}
\hline \multicolumn{3}{|c|}{ El Niño } & \multicolumn{3}{c|}{ La Niña } \\
\hline Fraco & Moderado & Forte & Fraco & Moderado & Forte \\
\hline 1969 & 1951 & 1957 & 1950 & 1955 & 1973 \\
\hline 1976 & 1963 & 1965 & 1954 & 1970 & 1975 \\
\hline 1977 & 1968 & 1972 & 1956 & 1998 & 1988 \\
\hline 2004 & 1986 & 1982 & 1962 & 2007 & 1999 \\
\hline 2006 & 1987 & 1997 & 1964 & & 2010 \\
\hline & 1991 & & 1967 & & \\
\hline & 1994 & & 1971 & & \\
\hline & 2002 & & 1974 & & \\
\hline & 2009 & & 1984 & & \\
\hline & & & 1995 & & \\
\hline & & & 2000 & & \\
\hline & & & 2011 & & \\
\hline
\end{tabular}

Fonte: NOAA - National Weather Service. 
Os dados das maiores intensidades dos fenômenos climáticos El Niño e La Niña na região $3.4^{2}$ (Quadro 2 e Figura 4), nas coordenadas $5^{\circ} \mathrm{N}$ a $5^{\circ} \mathrm{S}$ e $120^{\circ}$ a $170^{\circ} \mathrm{W}$, foram obtidos do Serviço Climatológico Nacional dos estados Unidos (NOAA - National Weather Service).

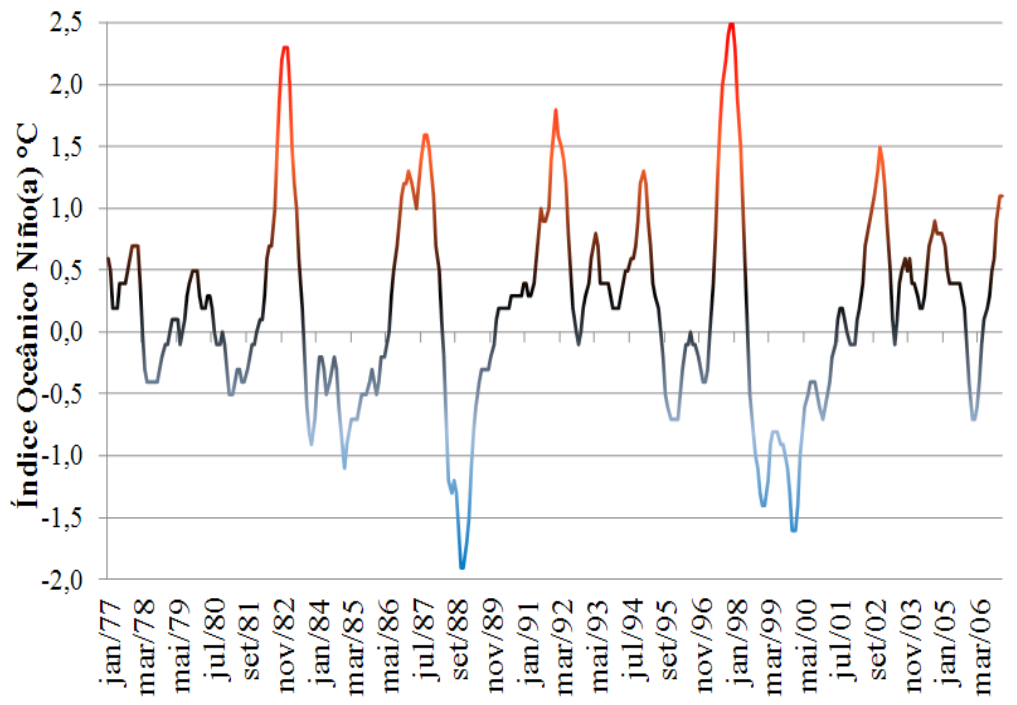

Figura 4. Índice Oceânico Niño(a) de 1977 a 2006

Fonte: NOAA - National Weather Service.

O ION (Índice Oceânico Niño(a)) é um índice que identifica as anomalias da superfície do oceano Pacífico através de uma média móvel de três meses. Quando o ION for maior que $+0,5^{\circ} \mathrm{C}$ por, no mínimo, cinco meses consecutivos, o período é caracterizado como El Niño e, quando o índice for menor que $-0,5^{\circ} \mathrm{C}$ por, no mínimo, cinco meses consecutivos, o período é caracterizado como La Niña, assim variações de até 0,5 graus na temperatura das águas do Oceano Pacífico são consideradas normais.

${ }^{2}$ ttp://www.ncdc.noaa.gov/teleconnections/enso/indicators/sst.php 


\section{Resultados E Discussão}

Tendência do Número de Dias de Chuva Mensais no Mato Grosso

Considerou-se dia chuvoso neste estudo aquele com precipitação pluvial acima de o,1 mm (Da Silva et al., 2011). A distribuição dos Números de Dias de Chuvas das médias mensais, com base nos dados da série histórica de 1977 a 2006, registradas em 120 estações pluviométricas, distribuídas no estado do Mato Grosso, apresenta uma variação significativa, em sua maioria, de diminuição de NDC.

O maior NDC observado no estado do Mato Grosso, para o mês de janeiro (Figura 5(a)), foi de 22 no ano de 1985, caracterizado por um período de La Niña fraco (Quadro 2 e Figura 4). O menor foi de 11 no ano de 1993, totalizando uma variação do maior para o menor NDC, para a série histórica estudada, de 50,2\%. Para o período de 1977 a 2006, observou-se uma tendência média de redução do NDC de -5,8\% no mês de janeiro.

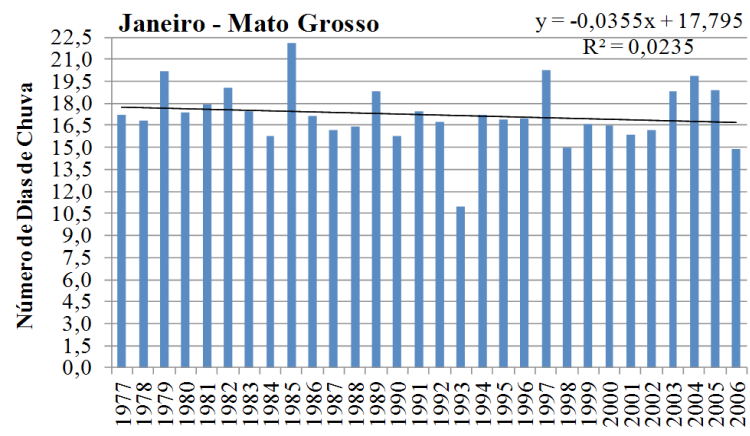

Figura 5(a). Tendência de NDC no mês de janeiro em Mato Grosso 
O maior NDC observado no estado do Mato Grosso, para o mês de fevereiro (Figura 5(b)), foi de 20,7 no ano de 1980. O menor foi de 12 no ano de 2005 , totalizando uma variação do maior para o menor NDC, para a série histórica estudada, de $41,1 \%$. Observou-se uma tendência média de redução do NDC na ordem de -0,9\% no mês de fevereiro.

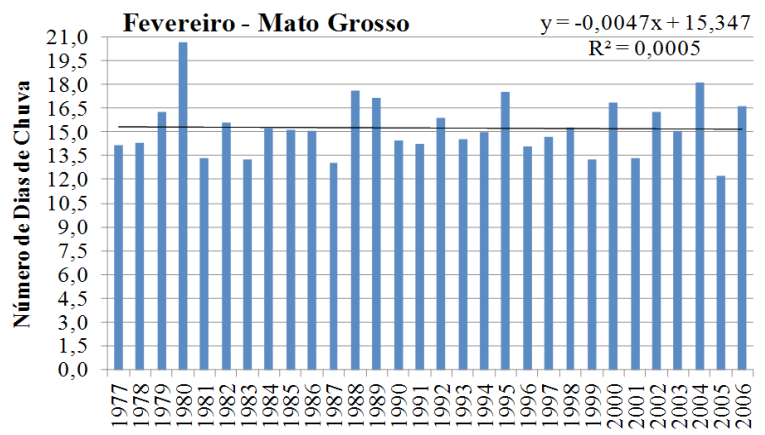

Figura 5(b). Tendência de NDC no mês de fevereiro em Mato Grosso

O maior NDC para o mês de março (Figura 5(c)), observado no estado do Mato Grosso, foi de 18 no ano de 2003 (final de um período de El Niño moderado, Figura 4 e Quadro 2) e o menor foi de 10 no ano de 1993, totalizando uma variação do maior para o menor NDC, para a série histórica estudada, de 44,8\%. Para o período de 1977 a 2006, observou-se uma tendência média de crescimento do NDC de 6,3\% no mês de março, sendo este o único mês em que houve tendência positiva de NDC para a série histórica estudada no estado do Mato Grosso.

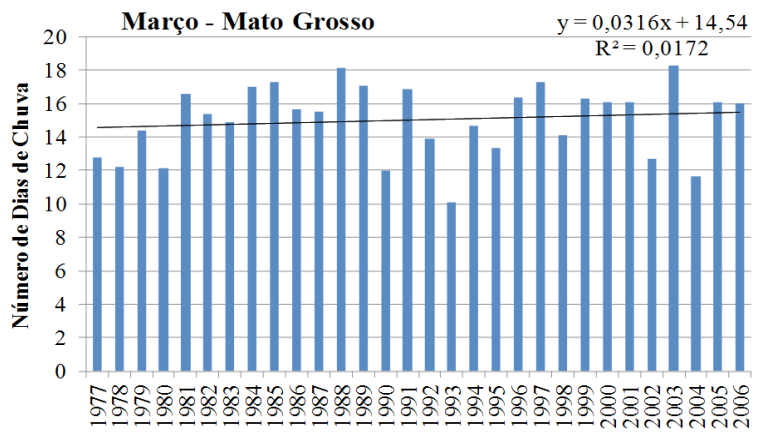

Figura 5(c). Tendência de NDC no mês de março em Mato Grosso 
O maior NDC para o mês de abril (Figura 5(d)), observado no estado do Mato Grosso, foi de 15 no ano de 1985 (período de La Niña fraca, Figura 4 e Quadro 2) e o menor foi de 6 no ano de 2002, totalizando uma variação do maior para o menor NDC, para a série histórica estudada, de 57,2\%. Observou-se uma tendência média de redução do NDC de $-7,5 \%$ no mês de abril.

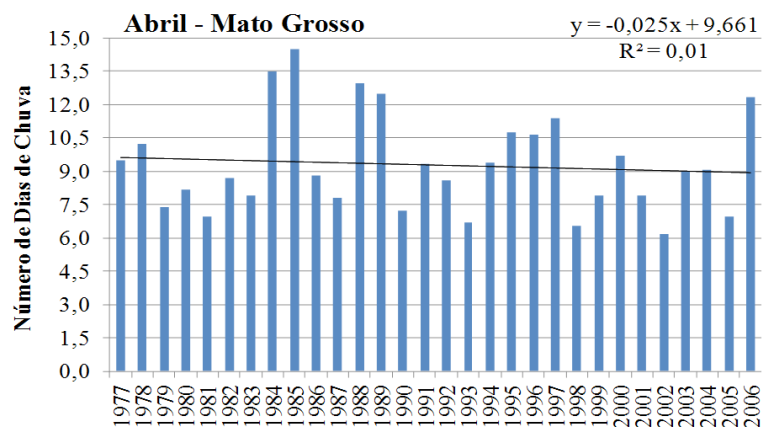

Figura 5(d). Tendência de NDC no mês de abril em Mato Grosso

No mês de maio (Figura 5(e)), o maior NDC observado, no estado do Mato Grosso, foi de 7 no ano de 1977 e o menor foi de 1 no ano de 1981, totalizando uma variação do maior para o menor NDC, para a série histórica estudada, de 78,8\%. Para o mês de maio, observou-se uma tendência média de decréscimo do NDC de -35,6\%.

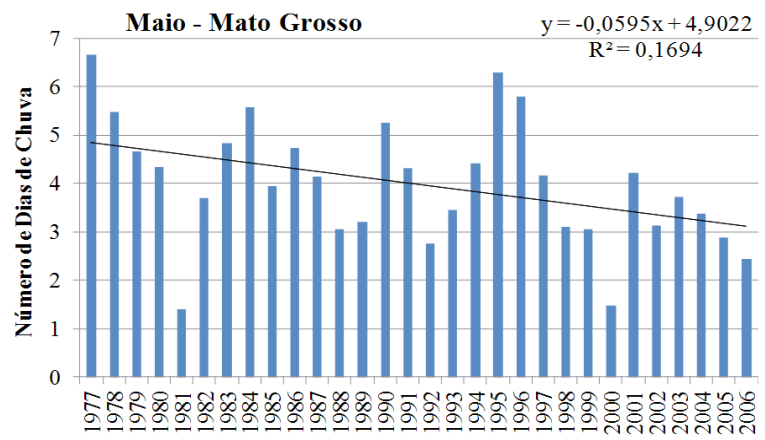

Figura 5(e). Tendência de NDC no mês de maio em Mato Grosso

No mês de junho (Figura 5(f)), o maior NDC observado, no estado do Mato Grosso, foi de 4 no ano de 1977. O menor foi de 0,2 nos anos de 2002 (início de um período de aquecimento das águas do Oceano 
Pacífico, Figura 4 e Quadro 2) e 2006 (com a temperatura do Oceano Pacífico próxima da neutralidade), totalizando uma variação do maior para o menor NDC, para a série histórica estudada, de 95,2\%. Para o mês de junho, no período de 1977 a 2006, observou-se uma tendência média de decréscimo do NDC de -57,1\%.

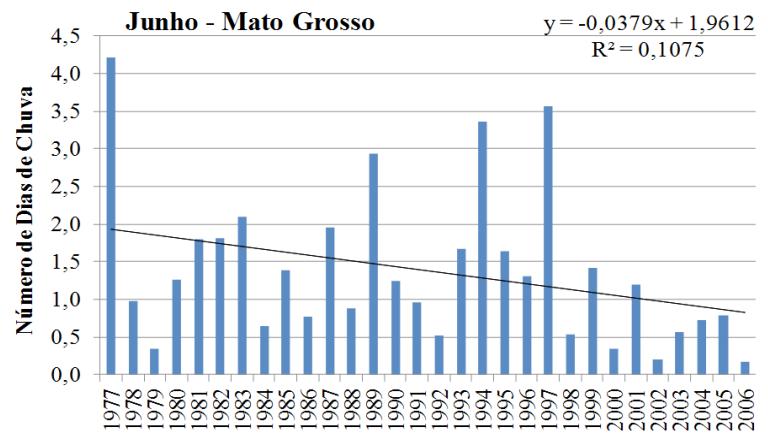

Figura 5(f). Tendência de NDC no mês de junho em Mato Grosso

No mês de julho (Figura 6(a)), o maior NDC observado, no estado do Mato Grosso, foi de 30, no ano de 1978, e o menor foi de o,o8, no ano de 1988 (ano de forte La Niña - Quadro 2 e Figura 4), totalizando uma variação do maior para o menor NDC, para a série histórica estudada, de $97,3 \%$. Para o mês de julho, observou-se uma tendência média de decréscimo do NDC de $-41,5 \%$.

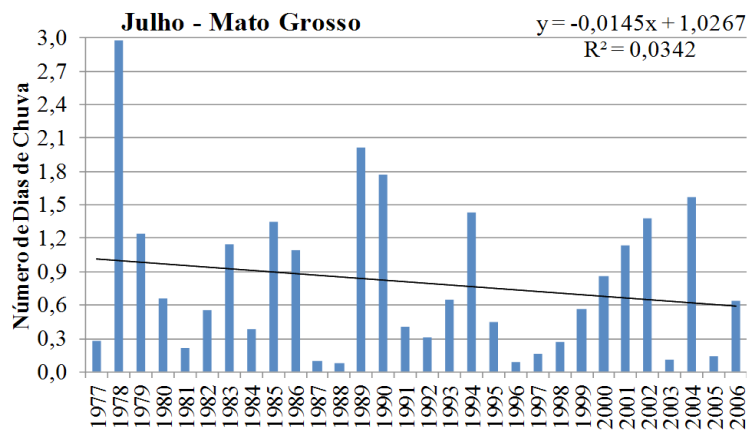

Figura 6(a). Tendência de NDC no mês de julho em Mato Grosso

Para o mês de agosto (Figura 6(b)), o maior NDC observado, no estado do Mato Grosso, foi de 5 no ano de 1986 (início do aquecimento das 
águas do Oceano Pacífico, Figura 4 e Quadro 2). O menor foi de o, 1 no ano de 1988 (ano de forte La Niña - Quadro 2 e Figura 4), totalizando uma variação do maior para o menor NDC, para a série histórica estudada, de $100 \%$. Para o mês de agosto, observou-se uma tendência média de decréscimo do NDC de -35,2\%.

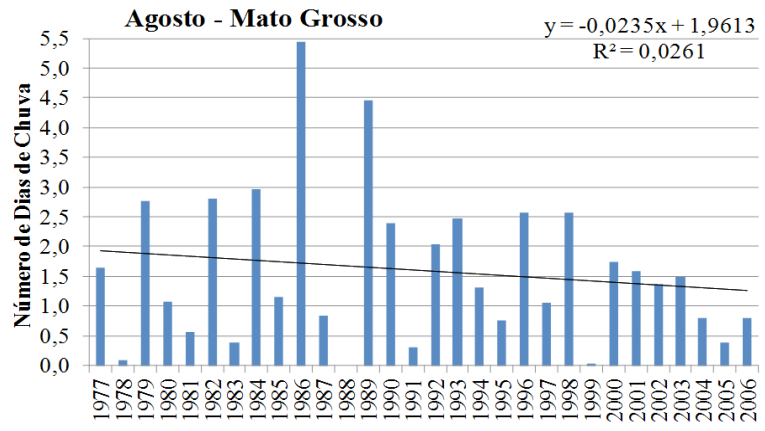

Figura 6(b). Tendência de NDC no mês de agosto em Mato Grosso

Para o mês de setembro (Figura 6(c)), o maior NDC observado, no estado do Mato Grosso, foi de 9 no ano de 1982 (início de um período de forte aquecimento das águas do Oceano Pacífico, Figura 4 e Quadro 2) e o menor foi de 2 no ano de 1988 (ano de forte La Niña - Quadro 2 e Figura 4). Totalizando uma variação do maior para o menor NDC, para a série histórica estudada, de 79,8\%. Para o mês de setembro, no período de 1977 a 2006, observou-se uma tendência média de decréscimo do NDC de $-19,4 \%$.

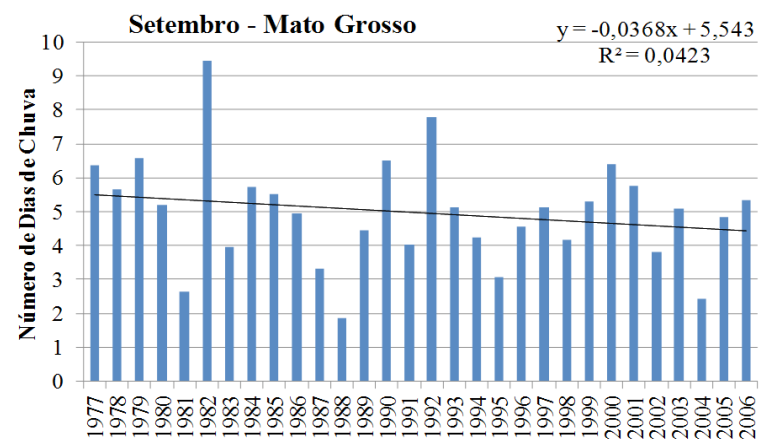

Figura 6(c). Tendência de NDC no mês de setembro em Mato Grosso 
Para o mês de outubro (Figura 6(d)), o maior NDC observado, no estado do Mato Grosso, foi de 13 no ano de 1984 (início de um período de esfriamento das águas do Oceano Pacífico, Figura 4). O menor foi de 6 no ano de 1979, totalizando uma variação do maior para o menor NDC, para a série histórica estudada, de 52,2\%. Para o mês de outubro, no período de 1977 a 2006, observou-se uma tendência média de decréscimo do NDC de -0,2\%.

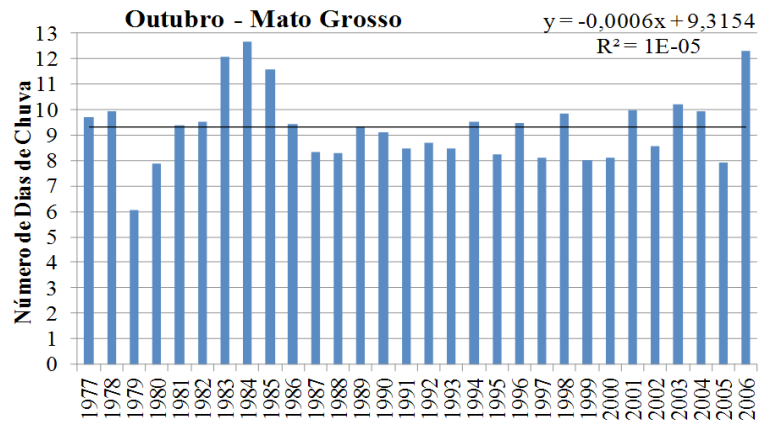

Figura 6(d). Tendência de NDC no mês de outubro em Mato Grosso

No mês de novembro (Figura 6(e)), o maior NDC observado, no estado do Mato Grosso, foi de 15 no ano de 2001 e o menor foi de 9 no ano de, totalizando uma variação do maior para o menor NDC, para a série histórica estudada, de 39,2\%. Para o mês de novembro, no período de 1977 a 2006, observou-se uma tendência média de decréscimo do NDC de -7,7\%.

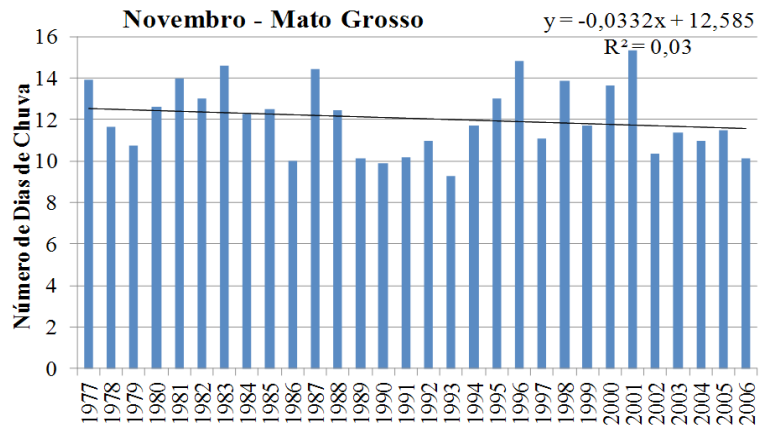

Figura 6(e). Tendência de NDC no mês de novembro em Mato Grosso

Para o mês de dezembro (Figura 6(f)), o maior NDC observado, no estado do Mato Grosso, foi de 19 no ano de 1989 e o menor foi de 13 no 
ano de 1990, totalizando uma variação do maior para o menor NDC, para a série histórica estudada, de 33,9\%. Para o mês de dezembro, no período de 1977 a 2006 , observou-se uma tendência média de decréscimo do NDC de $-6,3 \%$.

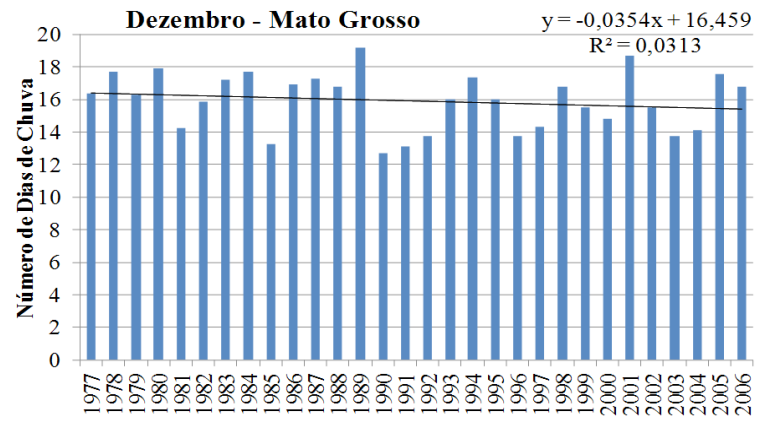

Figura 6(f). Tendência de NDC no mês de dezembro em Mato Grosso

\section{Tendência do Número de Dias de Chuva Anual Total no Mato Grosso}

O maior NDC observado no estado do Mato Grosso, para a soma histórica anual (Figura 7), foi de 121 no ano de 1989 (fim de um período forte de La Niña - Figura 4). O menor NDC foi de 89 no ano de 1993 (período sem El Niño ou La Niña - Figura 4 e Quadro 2). A variação do maior para o menor foi de $26,3 \%$. Observa-se também que as oscilações interanuais não são bruscas, e as tendências de decréscimo do NDC total anual fica, em média, na ordem de $-7,2 \%$ de 1977 a 2006.

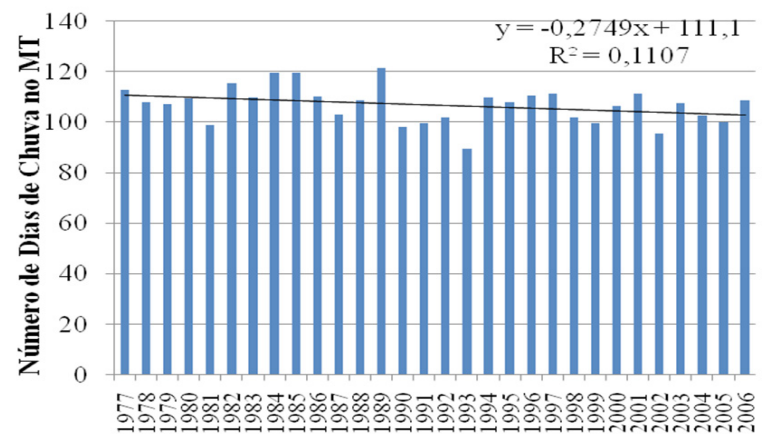

Figura 7. Tendência de NDC interanual no Mato Grosso 


\section{Distribuição Mensal do Número de Dias de Chuva}

Na Figura 8, verifica-se a distribuição média do Número de Dias de Chuva nos meses do ano, para o período de 1977 a 2006. Verificam-se também as máximas, mínimas e a tendência polinomial média no decorrer dos meses do ano.

Observa-se que, em média, o mês de janeiro possui o maior NDC médio (22), além da maior máxima média (13) e a menor mínima média (1) no ano. Verifica-se que, em média, o mês de agosto possui o menor NDC $(0,1)$ no Mato Grosso e a menor máxima média (3) em julho. Já a menor mínima média $(0,1)$ no ano foi observada no mês de agosto.

Na Figura 9, observa-se que, na evolução média da década, do período de 30 anos estudado, houve uma tendência média de diminuição dos dias de chuva para os meses do ano, no estado do Mato Grosso, década após década, conforme relatado na discussão das Figuras 5 e 6 , havendo poucas exceções. O mês de fevereiro pode ter um menor NDC em relação março, demonstrado na "queda" gráfica da Figura 9, porque tem apenas 28 dias (ou 29 a cada quatro anos).

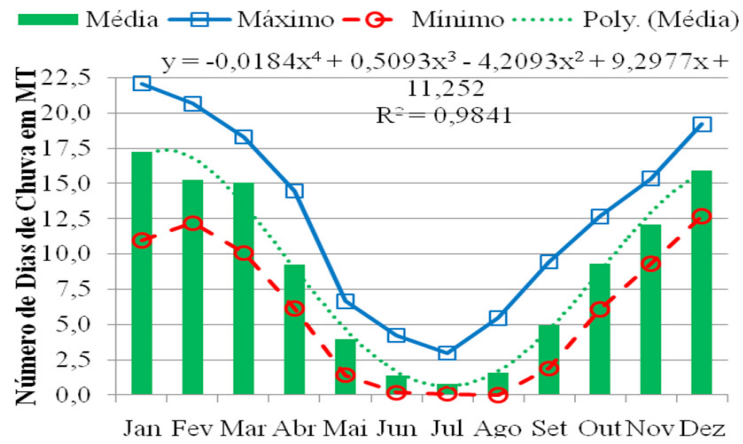

Figura 8. Histograma de NDC da média mensal, suas máximas, mínimas e tendência polinomial 


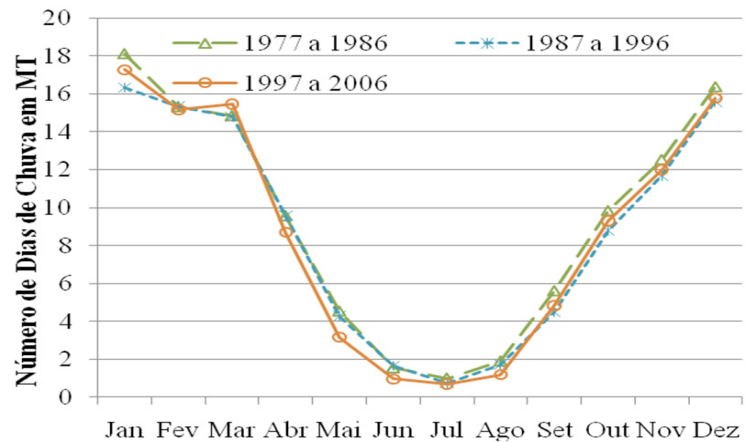

Figura 9. Evolução do NDC da média mensal, para três períodos de 10 anos, entre 1977 e 2006.

\section{Análise estatística do NDC do estado do Mato Grosso}

$\mathrm{Na}$ análise estatística (Tabela 1), verifica-se que o máximo NDC do estado do Mato Grosso foi obtido no mês de janeiro $(22,1)$ de 1985 , quando o Índice Oceânico Niño estava em $-0,9^{\circ} \mathrm{C}$, ou seja, passando por La Niña de intensidade fraca (Figura 4).

Tabela 1. Análise estatística do NDC do Mato Grosso (1977 a 2006).

\begin{tabular}{cccccc}
\hline Meses & Máx. & Méd. & Med. & Mín. & Des. Padrão \\
\hline Jan & 22 & 17 & 17 & 11 & 2,0 \\
Fev & 21 & 15 & 15 & 12 & 1,8 \\
Mar & 18 & 15 & 16 & 10 & 2,1 \\
Abr & 15 & 9 & 9 & 6 & 2,2 \\
Mai & 7 & 4 & 4 & 1 & 1,3 \\
Jun & 4 & 1 & 1 & 0 & 1,0 \\
Jul & 3 & 1 & 1 & 0 & 0,7 \\
Ago & 5 & 2 & 1 & 0 & 1,3 \\
Set & 9 & 5 & 5 & 2 & 1,6 \\
Out & 13 & 9 & 9 & 6 & 1,4 \\
Nov & 15 & 12 & 12 & 9 & 1,7 \\
Dez & 19 & 16 & 16 & 13 & 1,8 \\
Anual & 121 & 107 & 108 & 89 & 7 \\
\hline
\end{tabular}


A tendência central (média), que é o centro de um grupo de números em uma distribuição estatística, para os valores de NDC, mostrou uma maior proximidade com os valores máximos nos meses chuvosos (setembro a abril), em relação aos meses secos, que tiveram maior proximidade com os valores mínimos. Nos meses mais úmidos, verifica-se que a mediana ficou muito próxima da média e se distanciando dela nos meses mais secos. A medida do grau de dispersão dos valores, em relação ao seu valor médio, mostra que, em média, nos meses de maior NDC (meses mais chuvosos), o desvio padrão foi relativamente maior que nos meses com menores valores (meses mais secos). O maior desvio padrão foi obtido no mês de abril $(2,2)$, considerado o último mês úmido do ano hidrológico para o estado (Marcuzzo et al., 2011), e o menor desvio padrão foi obtido no mês de julho $(0,7)$, considerado mês seco. Em um estudo realizado na região nordeste do Brasil, Silva et al. (2011) concluíram que os maiores valores de NDC em grande parte da região ocorrem no primeiro semestre do ano, em face da atuação da ZCIT (Zona de Convergência Intertropical) e do DOL (Distúrbios Ondulatórios de Leste).

\section{Conclusão}

Entre os anos de 1977 a 2006, no estado do Mato Grosso, verificou-se, para as 120 estações pluviométricas estudadas, um decréscimo médio anual no NDC de $-7,2 \%$.

Nos meses de primavera e verão, obtiveram-se os maiores valores médios de NDC, para o período estudado, ficando os meses de outono e inverno com os menores valores. O mês de janeiro é o que possui maior NDC médio $(7,2)$ e o mês de julho o menor NDC médio do Mato Grosso $(0,8)$.

Observou-se que apenas o mês de março apresentou tendência de aumento (de $+6,3 \%$ ) do NDC, para a série histórica estudada de 30 anos, ficando os outros meses e a média geral anual com tendência de decréscimo no NDC do estado Mato-Grossense. O ENOS sem influência estatística significativa nos valores máximos e mínimos do NDC.

Em ordem decrescente, os meses que apresentaram tendência de decréscimo no NDC no estado do Mato Grosso, entre 1977 e 2006, foram: junho, julho, maio, agosto, setembro, novembro, abril, dezembro, janeiro, fevereiro e outubro. 


\section{Agradecimentos}

Os autores agradecem à CPRM/SGB (Companhia de Pesquisa de Recursos Minerais/Serviço Geológico do Brasil - Empresa Pública de Pesquisa do Ministério de Minas e Energia), pelo fomento que viabilizou o desenvolvimento deste trabalho.

Referências

BAZZANO, M. G. P.; ELTZ, F. L. F.; CASSOL, E. A. Erosividade, Coeficiente de chuva, padrões e período de retorno das chuvas de Quaraí, RS. Revista Brasileira Ciência do Solo. 2007, v. 31, n. 5, p. 1205-1217. (http:// dx.doi.org/10.1590/So100-06832007000500036).

BRUNETTIA, M.; MAUGERIB, M.; NANNIA, T. Changes in total precipitation, rainy days and extreme events in northeastern Italy. International Journal of Climatology, v. 21, n. 1, p. 861-871, 2001. (http://dx.doi. org/10.1002/joc.660).

DA SILVA, V. P. R.; PEREIRA, E. R. R.; DE AZEVEDO, P. V.; DE SOUSA, F. de A. S.; DE SOUSA, I. F. Análise da pluviometria e dias chuvosos na região Nordeste do Brasil. Revista Brasileira de Engenharia Agrícola e Ambiental. v. 15, n. 2, p. 131-138, 2011. Disponível em: < http:// www.scielo.br/pdf/rbeaa/v15n2/v15no2a04.pdf>. Acesso em 19 de fevereiro de 2013 .

FISCHER, G. R.; DINIZ, G. B.; MARQUES, J. R. Q. Previsão do número de dias de chuva para a metade sul do Rio Grande do Sul utilizando a Temperatura da Superfície do Mar (TSM). Revista Brasileira de Meteorologia. São Paulo, v. 23, n. 2, 2008. Disponível em: <http://www.scielo.br/ scielo.php?script=sci_arttext\&pid=S0102-77862008000200003\&ln $\mathrm{g}=\mathrm{en} \& \mathrm{nrm}=\mathrm{iso}>$. Acessado em 6 de agosto de 2012. (http://dx.doi. org/10.1590/So102-77862008000200003).

GALVANI, E. Estatística Descritiva em sala de aula. In: Luis Antonio Bittar Venturi. (Org.). Geografia: Práticas de campo, laboratório e sala de aula. São Paulo: Sarandi, 2011, v. 1, p. 469-482.

IBGE 2010. Disponível em: <http://www.censo2010.ibge.gov.br/resultados_do_censo2010.php>. Acessado em or de março de 2011. 
MARCUZZO, F. F. N.; COSTA, H. de C. Estudo da Sazonalidade das Chuvas no estado do Mato Grosso do Sul e Sua Distribuição Espaço-Temporal. Revista Brasileira de Geografia Física. v. 5, n. 1, 2012, p. 7386. Disponível em: <http://www.ufpe.br/rbgfe/index.php/revista/article/view/264/253>. Acessado em 7 de agosto de 2012.

MARCUZZO, F. F. N.; MELO, D. C. R.; ROCHA, H.M. Distribuição Espaço-Temporal e Sazonalidade das Chuvas no estado do Mato Grosso. Revista Brasileira de Recursos Hídricos. v. 16, n.4, 2011, p. 157-167. Disponível em: <http://www.abrh.org.br/novo/detalha.php?id=649 $\& \mathrm{t}=$ Distribui\%E7\%E30+Espa\%E7o-Temporal+e+Sazonalidade+das+ Chuvas+no+Estado+do+Mato+Grosso $>$. Acessado em 5 de agosto de 2012.

MELLAART, E.A.R. Small-scale spatial rain distribution: the effect of temporal and spatial rain distribution on drought and crop yield at village level. Nelspruit: Institute for Soil, Climate and Water, 1999. $18 \mathrm{p}$.

MELLO, C. R.; FERREIRA, D. F.; SILVA, A. M.; LIMA, J. M. Análise de modelos matemáticos aplicados ao estudo de chuvas intensas. Revista Brasileira de Ciência do Solo. Viçosa, v. 25, n. 3, 2001, p. 693-698. Disponivel em: < http://sbcs.solos.ufv.br/solos/revistas/v25n3al 8.pdf>. Acessado em 3 de agosto de 2012.

MELLO, C. R.; SILVA, A. M. Modelagem estatística da precipitação mensal e anual e no período seco para o estado de Minas Gerais. Revista Brasileira de Engenharia Agrícola e Ambiental. v. 13, n. 1, 2009, p. 68 74. (http://dx.doi.org/10.1590/S1415-43662009000100010).

MELLO, C. R.; VIOLA, M. R.; MELLO, J. M.; SILVA, A. M. Continuidade espacial de chuvas intensas no estado de Minas Gerais. Ciência e Agrotecnologia. v. 32, n. 2, 2008, p. 532-539. doi: (http://dx.doi.org/10.1590/ S1413-70542008000200029).

NAGHETTINI \& PINTO. Hidrologia Estatística. Belo Horizonte: CPRM, 2007. 552p.

PEEL M.C.; FINLAYSON B.L.; McMAHON T.A. Updated world map of the Köppen-Geiger climate classification. Hydrology Earth System 
Science. 2007, v. 11, p. 1633-1644. Disponível em: <http://www.hydrol-earth-syst-sci.net/11/1633/2007/hess-11-1633-2007.pdf>. Acessado em 20 de julho de 2012 .

SETTE, D. M. Os climas do cerrado do centro-oeste. Revista Brasileira de Climatologia. v. 1, n. 1, 2006, p. 29-42. Disponível em: <http://www. geografia.fflch.usp.br/abclima/revista/vol_1/3_denise.pdf>. >. Acessado em 19 de fevereiro de 2013.

SILVA, V. P. R.; PEREIRA, E. R. R.; ALMEIDA, R. S. R. Estudo da variabilidade anual e intra-anual da precipitação na região Nordeste do Brasil. Revista Brasileira de Meteorologia. São Paulo. v. 27, n. 2, 2012. Disponível em: <http://www.scielo.br/scielo.php?script=sci_arttext\&pid=S0102$-77862012000200005 \& \operatorname{lng}=e n \& n r m=i s o>$. Acessado em 5 de agosto de 2012. (http://dx.doi.org/10.1590/S0102-77862012000200005).

SILVA, V.P.R.; PEREIRA, E.R.R.; AZEVEDO, P.V.; CAMPOS, J.H.B.C, BRAGA, R.C. Estudo da variabilidade anual e intra-anual da precipitação e do número de dias chuvosos no estado da Paraíba. Revista Ciência da Vida. v. 29, n. 1, 2009, p.50-62. Disponível em: <http://silvavpr.files. wordpress.com/2010/08/2009-paper-ciencia-da-vida-m.pdf>. Acessado em 7 de agosto de 2012 .

STRAHLER, A.N. Geografia física. Barcelona, Omega. 1977. 767 p.

Submetido em: $05 / 11 / 2012$

Aceito em: 20/02/2013 